\title{
Adaptabilidade e estabilidade de genótipos de girassol para a região subtropical do Brasil
}

\author{
Adaptability and stability of sunflower genotypes for the sub-tropical region of Brazil
}

\author{
Willyam Stern Porto ${ }^{\mathrm{I}}$ Claudio Guilherme Portela de CarvalhoI** Ronald José Bart Pinto ${ }^{\mathrm{I}}$ \\ Marcelo Fernandes de Oliveira" ${ }^{\text {II }}$ Ana Cláudia Barneche de Oliveira' ${ }^{\text {II }}$
}

\section{RESUMO}

O sucesso da cultura do girassol (Helianthus annuus L.) no Brasil está associado à escolha adequada de cultivares com adaptação a diferentes ambientes. Quando há respostas diferenciadas dos genótipos testados nos diferentes ambientes, a decisão de lançamento de novas cultivares pode ser facilitada com estudos de adaptabilidade e estabilidade desses genótipos para reduzir os efeitos da interação genótipos $x$ ambientes. No país, essas informações tornam-se mais importantes, pois a maioria das cultivares utilizadas, ou em lançamento, foram desenvolvidas em outros países, com características de solo e clima diferentes. Este trabalho teve como objetivo estudar a adaptabilidade e estabilidade de genótipos de girassol na região subtropical do Brasil, uma das regiões promissoras do país para o seu cultivo. Os dados foram obtidos da Rede Nacional de Ensaios de Avaliação de Genótipos de Girassol, coordenada pela Embrapa Soja, entre os anos de 1999/2000 e 2003/2004. Os caracteres avaliados foram rendimentos de grãos e de óleo ( $\left.\mathrm{kg} \mathrm{ha}^{-1}\right)$. Os estudos de adaptabilidade e estabilidade foram realizados segundo as metodologias de PORTO et al. (2007), EBERHART \& RUSSELL (1966) e ROCHA et al. (2005), as quais utilizam procedimentos biométricos distintos. Diferente do método de EBERHART \& RUSSELL (1966), o de PORTO et al. (2007) selecionou genótipos que, apesar de terem médias gerais inferiores às testemunhas, tiveram bons desempenhos em ambientes específicos. Esse método foi mais rigoroso em selecionar genótipo, em relação ao de ROCHA et al. (2005). Para rendimento de grãos, o genótipo ACA 884 apresentou indicação para ambientes em geral, EM 677008, Agrobel 930 e GV 26048 foram indicados para ambientes favoráveis, $e$ ACA 885, para os desfavoráveis. Para rendimento de óleo, ACA 884 teve indicação geral, GV 26048, CF 17, Agrobel 972 e Helio 358 tiveram indicação para ambientes favoráveis, e HT 01 e ACA 885, para os desfavoráveis.

Palavras-chave: Helianthus annuus, interação genótipos $x$ ambientes, melhoramento genético.

\begin{abstract}
The success of sunflower crop in Brazil is associated to the choice of adapted cultivars to different environments. When there are different genotypes answers in different environments, the release of new cultivars can be facilitated by carrying out studies of adaptability and stability of these genotypes to reduce the effects of genotypes $x$ environments interaction. In Brazil, this information become more important, therefore the main cultivars had been developed in others countries, with different soil traits and climate. The objective of this study was to select sunflower genotypes for the sub-tropical region of Brazil. Experimental data from 1999/2000 to 2003/ 2004 were obtained by the National Sunflower Trials, coordinated by Embrapa Soja. The evaluated traits were grain and oil yields $\left(\mathrm{kg} \mathrm{ha}^{-1}\right)$. It was carried out a study of adaptability and stability of genotypes according to the methods proposed by PORTO et al. (2007), EBERHART \& RUSSELL (1966) and ROCHA et al. (2005). Differently from the method of EBERHART \& RUSSELL (1966), PORTO et al. (2007) selected genotypes, that despite of its lower overall average in relation to reference standard had good performance in specific environments. This method was more rigorous to select genotypes, when compared with ROCHA et al. (2005). For grain yield, genotype ACA 884 was indicated for general environments, EM 677008, Agrobel 930 and GV 26048 were indicated for favorable environments and ACA 885 for the unfavorable environments. In the same way, for oil yield, ACA 884 had general indication, GV 26048, CF 17, Agrobel 972 and Helio 358 are indicated for favorable environments and HT 01 and ACA 885 for the unfavorable ones.
\end{abstract}

Key words: Helianthus annuus, interaction genotypes $x$ environments, genetic breeding.

\section{INTRODUÇÃO}

O girassol (Helianthus annuus L.) destacouse, na safra 2007, como quinta oleaginosa em produção

'Departamento de Agronomia, Universidade Estadual de Maringá (UEM), Maringá, PR, Brasil.

${ }^{I}$ Embrapa Soja, CP 231, 86001-970, Londrina, PR, Brasil. E-mail: cportela@cnpso.embrapa.br. *Autor para correspondência. 
de grãos e em área cultivada (27,53 milhões de toneladas e 22,76 milhões de hectares, respectivamente), no mundo (ESTADOS UNIDOS, 2008). No Brasil, apesar da área de cultivo, nessa safra, ter sido de apenas 99 mil hectares (REUNIÃO, 2007), vem crescendo o interesse de produtores pelo seu plantio devido à busca por novas opções de cultivo e ao aumento da demanda das indústrias por óleo de melhor qualidade e, principalmente, para produção de biocombustíveis. Dentre as regiões promissoras no país, inclui-se a subtropical. Nos Estados do Rio Grande do Sul e Paraná, por exemplo, entre 2001/2002 e 2006/2007, a área cultivada aumentou em 600 e 400\%, respectivamente (REUNIÃO, 2007).

Por ser uma cultura relativamente nova no país, é de grande importância a obtenção de informações agronômicas sobre os genótipos disponíveis por meio da pesquisa, pois torna-se possível selecionar e recomendar aqueles genótipos mais adaptados às regiões produtoras, o que consequentemente pode aumentar o sucesso do produtor com a cultura, com maiores produtividades e retornos econômicos competitivos com outras lavouras já estabelecidas. Essas informações são, também, relevantes, pois a maioria das cultivares utilizadas ou em lançamento foram desenvolvidas em outros países, com características de solo e clima diferentes.

Quando há resposta diferenciada dos genótipos às diferentes regiões produtoras, ela pode dificultar a escolha de novas cultivares. A influência da interação genótipos $\mathrm{x}$ ambientes pode ser reduzida por meio de estudos de adaptabilidade e estabilidade dos genótipos. Diversas metodologias já foram desenvolvidas para realizar esses estudos e descritas, dentre outros, por CRUZ \& CARNEIRO (2003). Segundo esses autores, a diferença entre as metodologias origina-se nos parâmetros adotados para a sua avaliação, nos procedimentos biométricos utilizados para avaliá-la ou na informação ou no detalhamento de sua análise. Além disso, muitos trabalhos foram realizados para comparar essas metodologias, na tentativa de indicar os mais práticos e eficazes aos objetivos do melhoramento genético de plantas.

Para gerar informações sobre o desempenho de genótipos de girassol, desde 1989, eles são avaliados pela Rede de Ensaios de Avaliação de Genótipos de Girassol, coordenada pela Embrapa Soja e conduzida em parceria com instituições públicas e privadas. $\mathrm{O}$ objetivo deste trabalho foi estudar a adaptabilidade e estabilidade dos genótipos de girassol quanto ao rendimento de grãos e de óleo, avaliados nessa Rede de Ensaios, entre 1999/2000 e 2003/2004, para a região subtropical do Brasil.

\section{MATERIAL E MÉTODOS}

Os dados analisados foram obtidos da Rede de Ensaios de Avaliação de Genótipos de Girassol conduzida entre 1999/2000 e 2003/2004, em diversos locais dos Estados do Rio Grande do Sul (RS), Santa Catarina (SC), Paraná (PR) e São Paulo (SP).

A semeadura dos ensaios foi realizada em agosto/setembro, sendo usado o delineamento experimental de blocos completos casualizados, com quatro repetições, com cada parcela constituída de quatro linhas de $6,0 \mathrm{~m}$ de comprimento, espaçadas de 0,7 a $0,9 \mathrm{~m}$. Na colheita, as duas linhas externas e $0,5 \mathrm{~m}$ de cada extremidade das linhas centrais foram descartadas como bordaduras, obtendo-se uma área útil na parcela de 7,0 a $9,0 \mathrm{~m}^{2}$, dependendo do espaçamento adotado. Foram realizados tratos culturais como adubação e capina para possibilitar o melhor desenvolvimento das plantas.

Os genótipos avaliados foram híbridos (simples e triplos) e variedades (populações de polinização aberta) das empresas Advanta, BRASKALB, CATI, Dow AgroSciences, Embrapa Soja, La Tijereta e Helianthus do Brasil. Foram utilizados como testemunhas os híbridos comerciais M 734 (Dow AgroSciences) e Agrobel 960 (La Tijereta). Foram mensuradas as características rendimento de grãos e de óleo $\left(\mathrm{kg} \mathrm{ha}^{-1}\right)$. No período de teste, foram avaliados 11 (2000/2001), nove (2001/2002), 12 (2002/2003) e 11 (2003/2004) genótipos na rede, em Ensaio Final de Primeiro Ano ( $1^{\circ}$ ano de avaliação), e em Ensaio Final de Segundo Ano ( $2^{\circ}$ ano de avaliação). Avaliações feitas em 2000/2001 incluíram dados experimentais obtidos do Ensaio Final de Primeiro Ano 1999/2000 e do Ensaio Final de Segundo Ano 2000/2001, com procedimento similar para os demais períodos de avaliação. Assim, cada grupo de genótipos foi avaliado por dois anos.

Nos Ensaios Finais de Primeiro Ano (EFPA), os locais avaliados e as respectivas instituições/ empresas responsáveis foram Campo Mourão (Cooperativa Mista Agropecuária do Brasil) e Londrina (Embrapa Soja), PR; Cruz Alta (Universidade de Cruz Alta) e Passo Fundo (Universidade de Passo Fundo), RS; e Campinas (Instituto Agronômico de Campinas) e Manduri (Coordenadoria de Assistência Técnica Integral), SP. Nos Ensaios Finais de Segundo Ano (EFSA), os locais (instituições/empresas) foram Curitiba (Pontifícia Universidade Católica do Paraná), Londrina 
(Embrapa Soja), Campo Mourão (Cooperativa Agroindustrial Mourãoense), Maringá (Universidade Estadual de Maringá), PR; Rio do Sul (Escola Agrotécnica Federal de Rio do Sul), SC; Ibirubá (Cooperativa Agrícola Mista de General Osório Ltda), Ijuí (Cooperativa Regional Tritícola Serrana Ltda) e Três de Maio (Cooperativa Agropecuária Alto do Uruguai Ltda.), RS; e Araras (Universidade Federal de São Carlos), Campinas (Instituto Agronômico de Campinas) e Manduri (Coordenadoria de Assistência Técnica Integral), SP.

Foram realizadas análises de variância para rendimento de grãos e óleo, avaliados em cada local e ano. Devido ao fato de os locais de teste nos EFPA não terem sempre sido os mesmos dos EFSA, foi realizada análise conjunta de ambientes (local e ano específicos) para cada grupo de genótipos. Nessas análises, sempre que a razão entre o maior e o menor quadrado médio residual foi inferior a sete, para rendimento de grãos, considerou-se existir homogeneidade das variâncias residuais obtidas nas análises individuais (PIMENTEL GOMES, 1985). Além disso, ensaios com coeficientes de variação superiores a $20 \%$ não foram considerados nas análises de variância conjuntas (PIMENTEL GOMES, 1985; CARVALHO et al., 2003).

Foi feito estudo de adaptabilidade e estabilidade dos genótipos com base nos métodos de EBERHART \& RUSSELL(1966), ROCHA et al. (2005)e PORTO et al. (2007), que apresentam procedimentos biométricos distintos: comparação de desempenhos em ambientes distintos, análise de regressão e componentes principais, respectivamente.

No método de PORTO et al. (2007), a média geral é decomposta em médias de ambientes favoráveis (MF) e desfavoráveis (MD). Quando um genótipo se destaca apenas nos ambientes favoráveis, pode ser indicado para esse tipo de ambiente, da mesma forma ocorre para ambientes desfavoráveis. Quando sua média for superior nos dois tipos de ambiente, pode ser indicado para ambientes em geral. Segundo VERMA et al. (1978), são considerados ambientes favoráveis aqueles cujas médias são superiores à média geral do ensaio e dos ambientes desfavoráveis, quando inferiores. No presente estudo, a superioridade dos genótipos em cada ambiente foi verificada pelo teste de Scott \& Knott, a 5\% de probabilidade de erro. Além disso, fez-se a comparação da média de cada genótipo com a média das médias das testemunhas, em que apenas aqueles que a superam são selecionados.

Segundo a metodologia de EBERHART \& RUSSEL (1966), o genótipo considerado ideal é aquele que apresenta média de rendimento elevada, adaptabilidade geral $\left(\beta_{1 \mathrm{i}}=1\right)$, mensurada pelos coeficientes de regressão, e estabilidade alta $\left(\sigma_{\mathrm{d}}^{2}=0 \mathrm{ou}\right.$ alto $\mathrm{R}^{2}$ ), avaliada pelos desvios da regressão. Nesse estudo, a superioridade dos genótipos foi verificada de modo similar ao realizado no método de PORTO et al. (2007).

No método de ROCHA et al. (2005), o ideótipo com máxima adaptabilidade geral é aquele que apresenta os valores máximos observados para todos os ambientes estudados (ideótipo I); o ideótipo com adaptabilidade específica a ambientes favoráveis apresenta máxima resposta em ambientes favoráveis e mínima resposta em ambientes desfavoráveis (ideótipo II); o ideótipo com adaptabilidade específica para ambientes desfavoráveis apresenta máxima resposta em ambientes desfavoráveis e mínima, em ambientes favoráveis (ideótipo III); e o ideótipo de mínima adaptabilidade apresenta os menores valores observados em todos os ambientes estudados (ideótipo IV). Para se avaliar a adaptabilidade dos genótipos de girassol, entre 1999/2000 e 2003/2004, foi feita a comparação de suas distâncias cartesianas das quatro referências ideais (ideótipos), usando componentes principais (ROCHA et al., 2005).

Para a realização das análises estatísticas, foi utilizado o programa computacional Genes (CRUZ, 2001).

\section{RESULTADOS E DISCUSSÃo}

Nas análises de variância conjuntas, para as duas características avaliadas, verificaram-se diferenças significativas entre genótipos pelo teste $\mathrm{F}$ (Tabela 1). Foram observadas, também, diferenças significativas na interação genótipos $\mathrm{x}$ ambientes, $\mathrm{o}$ que demonstra que os genótipos apresentaram mudanças em seus desempenhos em relação aos diferentes ambientes testados e justifica a realização de análise de adaptabilidade e estabilidade (Tabelas 2 e 3). A presença de interação $\mathrm{G} \times \mathrm{A}$, em testes de rendimento de girassol, também foi verificada por LU'QUEZ (2002), DE LA VEGA \& CHAPMAN (2006), PORTO et al. (2007) e PORTO et al. (2008).

Dentre os métodos de adaptabilidade e estabilidade utilizadas neste estudo, apenas os de EBERHART \& RUSSEL (1966) e PORTO et al. (2007) utilizam a média como parâmetro para discriminação de genótipos. Apesar de ter havido a presença de interação genótipos $\mathrm{x}$ ambientes, testes de médias foram realizados no processo seletivo, pois há o interesse em indicar genótipos para a região subtropical do Brasil e não para cada local de teste. Com base nos dados amostrais, o uso do teste de Scott-Knott não apontou diferenças significativas entre os genótipos de girassol 
Tabela 1 - Resumo das análises de variância conjuntas para rendimento de grãos e óleo $\left(\mathrm{kg} \mathrm{ha}^{-1}\right)$ de genótipos de girassol, avaliados na Rede Nacional de Ensaios de Girassol, coordenada pela Embrapa Soja, no período de $1999 / 2000$ a 2003/2004.

\begin{tabular}{|c|c|c|c|}
\hline F.V & G.L & Q.M ${ }^{1}$ (Grãos) & Q.M (Óleo) \\
\hline \multicolumn{4}{|l|}{ Safra $2000 / 2001^{2}$} \\
\hline Blocos/Ambientes & 18 & $124.864,50$ & $37.493,33$ \\
\hline Genótipos & 10 & $1.551 .637,83 * *$ & $232.441,32 * *$ \\
\hline Ambiente & 5 & $13.369 .840,03 * *$ & $2.460 .790,68 * *$ \\
\hline GxA & 50 & $348.018,29 * *$ & $70.347,41 * *$ \\
\hline Resíduo & 180 & $70.563,59$ & $18.690,18$ \\
\hline Média $^{3}$ & & 1832,09 & 807,30 \\
\hline$C V^{4}(\%)$ & & 14,49 & 16,93 \\
\hline \multicolumn{4}{|l|}{ Safra 2001/2002 } \\
\hline Blocos/Ambientes & 24 & $70.257,72$ & $16.265,69$ \\
\hline Genótipos & 8 & $1.464 .411,91 * *$ & $128.315,75^{\mathrm{ns}}$ \\
\hline Ambiente & 7 & $7.728 .860,47 * *$ & $1.651 .807,44^{* *}$ \\
\hline GxA & 56 & $337.704,09 * *$ & $75.493,04 * *$ \\
\hline Resíduo & 192 & $68.167,09$ & $14.177,02$ \\
\hline Média & & 1871,40 & 798,42 \\
\hline CV $(\%)$ & & 13,95 & 14,91 \\
\hline \multicolumn{4}{|l|}{ Safra $2002 / 2003$} \\
\hline Blocos/Ambientes & 15 & $107.617,58$ & $15.508,13$ \\
\hline Genótipos & 11 & $714.600,57 * *$ & $151.507,82 * *$ \\
\hline Ambiente & 4 & $5.650 .286,95 * *$ & $1.236 .387,85^{* *}$ \\
\hline GxA & 44 & $219.032,11 * *$ & $42.310,45 * *$ \\
\hline Resíduo & 165 & $42.472,05$ & $6.877,56$ \\
\hline Média & & 1489,00 & 523,23 \\
\hline CV $(\%)$ & & 13,84 & 15,84 \\
\hline \multicolumn{4}{|l|}{ Safra $2003 / 2004$} \\
\hline Blocos/Ambientes & 27 & 351936,46 & $69.490,73$ \\
\hline Genótipos & 10 & 1604900,54 & $209.835,09 * *$ \\
\hline Ambiente & 8 & 8014920,34 & $1.552 .722,28 * *$ \\
\hline GxA & 80 & 408164,15 & $64.739,63 * *$ \\
\hline Resíduo & 270 & 77849,37 & $14.650,83$ \\
\hline Média & & 1799,69 & 718,01 \\
\hline CV (\%) & & 15,50 & 16,85 \\
\hline
\end{tabular}

**significativo a $5 \%$ de probabilidade pelo teste $\mathrm{F}$. ${ }^{\text {ns }}$ não significativo a 5\% de probabilidade pelo teste F. ${ }^{1}$ QM: Quadrado médio. ${ }^{2}$ Avaliações realizadas em 2000/2001 incluíram os dados experimentais obtidos no Ensaio Final de Primeiro Ano 1999/2000 e Ensaio Final de Segundo Ano 2000/2001, com procedimento similar para os demais anos de avaliação. ${ }^{3}$ Média Geral, em kg ha ${ }^{-1} \cdot{ }^{4} \mathrm{CV}$ : Coeficiente de variação experimental, em \%.

na maior parte das avaliações, e essas diferenças somente foram detectadas quando houve grande diferença entre as médias. Outros autores citam situações semelhantes em seus estudos (PORTO et al., 2007; CARVALHO, 2008; PORTO et al., 2008). Nas safras 2000/2001 e 2001/2002, por exemplo, todos os genótipos tiveram médias em ambientes desvaforáveis similares às obtidas pelas testemunhas, quanto ao rendimento de óleo (Tabela 3). Além disso, nenhum genótipo superou as testemunhas em nenhum ambiente, para os dois caracteres avaliados (Tabelas 2 e 3). Quando isso ocorre, PORTO et al. (2007) sugerem que a comparação dos genótipos seja feita com base na média das testemunhas, em valores absolutos.

Ao realizar a análise de adaptabilidade dos genótipos de girassol, entre 1999/2000 e 2003/2004, pelo método de PORTO et al. (2007), quanto ao rendimento de grãos e adotando-se a média das testemunhas como critério de seleção, verificou-se que o híbrido ACA 884 (2003/2004) obteve indicação geral, enquanto EM 677008(2000/2001), Agrobel 930 (2000/2001) e GV 26048 (2001/2002) foram indicados para ambientes favoráveis e ACA 885 (2003/2004) apresentou bom desempenho nos ambientes desfavoráveis (Tabela 2). Em relação ao rendimento de óleo, ACA 884 (2003/2004) teve indicação geral, os híbridos GV 26048 (2001/2002), CF 17 (2001/ 2002), A 972 (2003/2004) e Helio 358 (2003/2004) foram indicados para ambientes favoráveis e HT 01 (2000/ 2001) e ACA 885 (2003/2004), para os desfavoráveis (Tabela 3). Em 2002/2003, essas análises não foram realizadas, pois nesses ensaios houve número de ambientes favoráveis e/ou desfavoráveis igual ou inferior a três.

Pelo método de EBERHART \& RUSSELL (1966), quanto a rendimento de grãos, o híbrido ACA $884(2003 / 2004)$ obteve adaptabilidade geral $\left(\beta_{1}=1\right)$, e os híbridos EM 677008 (2000/2001) e GV 26048 (2001/ 2002) foram adaptados para ambientes favoráveis $\left(\beta_{1}>1\right)$ (Tabela 2). Para rendimento de óleo, ACA 884 (2003/2004) eA $972(2003 / 2004)$ tiveram adaptabilidade geral e apenas GV 26048 (2001/2002) foi indicado para ambientes favoráveis (Tabela 3). Exceto para A 972 (2003/2004), esses resultados foram similares aos obtidos pelo método de PORTO et al. (2007). Contudo, como a seleção no primeiro método tem como base a média obtida em todos os ambientes testados, esse método não selecionou genótipos que, apesar de terem médias gerais inferiores às testemunhas, tiveram bons desempenhos em ambientes específicos, como indicado pelo método de PORTO et al. (2007) para Agrobel 930 (2000/2001 em rendimento de grãos), ACA 885 (2003/ 2004 em rendimento de grãos e de óleo), CF 17 (2001/ 2002 em rendimento de óleo), Helio 358 (2003/2004 em rendimento de óleo) e HT 01 (2000/2001 em rendimento de óleo).

Apesar de o método de PORTO et al. (2007) considerar, para seleção de genótipos, os seus desempenhos nos ambientes favoráveis e desfavoráveis, os autores mencionam que as análises das variâncias dos desvios da regressão $\left(\sigma^{2}{ }_{d}\right.$ e $\left.R^{2}\right)$ contribuem com informações adicionais sobre a resposta dos genótipos frente a variações ambientais. 
Tabela 2 - Parâmetros de adaptabilidade e estabilidade de genótipos de girassol, para rendimento de grãos $\left(\mathrm{kg}^{\mathrm{a}} \mathrm{a}^{-1}\right)$, obtidos por meio dos métodos de PORTO et al. (2007), EBERHART \& RUSSEL (1966) e ROCHA et al. (2005), avaliados entre os anos de 2000 e 2004.

\begin{tabular}{|c|c|c|c|c|c|c|c|}
\hline \multicolumn{8}{|c|}{ Rendimento de grãos $\left(\mathrm{kg} \mathrm{ha}^{-1}\right)$} \\
\hline $2000 / 2001^{1}$ & & ----PORTO & al. (2007)---- & ----EBER & ART \& RUSSE & (1966)---- & ROCHA et al. (2005) \\
\hline Genótipo & Média $^{2}$ & $\mathrm{MD}^{3}$ & $\mathrm{MF}^{4}$ & $\beta_{1}$ & $\sigma_{\mathrm{d}}^{2}$ & $\mathrm{R}^{2}$ & Classe \\
\hline EM $677008(\mathrm{H})^{5}$ & $2188,69 \mathrm{a}$ & $1556,10 \mathrm{a}$ & $2821,28 \mathrm{a}$ & $1,35^{6}$ & $134.614,30 * *$ & 82,18 & I \\
\hline M $734(\mathrm{H})$ & $2186,27 \mathrm{a}$ & $1777,97 \mathrm{a}$ & $2594,57 \mathrm{a}$ & $1,27^{6}$ & $208.136,16^{* *}$ & 73,30 & I \\
\hline Agrobel $960(\mathrm{H})$ & $2046,74 \mathrm{a}$ & $1596,03 \mathrm{a}$ & $2497,46 \mathrm{~b}$ & $1,01^{\mathrm{ns}}$ & $793,29^{\text {ns }}$ & 95,48 & II \\
\hline Agrobel $930(\mathrm{H})$ & $2036,07 \mathrm{a}$ & $1405,30 \mathrm{a}$ & $2666,85 \mathrm{a}$ & $1,24^{6}$ & $79.291,70^{* *}$ & 85,87 & II \\
\hline DK $4030(\mathrm{H})$ & 1929,19 a & $1562,04 \mathrm{a}$ & $2296,35 \mathrm{~b}$ & $1,02^{\mathrm{ns}}$ & $91.245,08^{* *}$ & 78,67 & I \\
\hline Agrobel $966(\mathrm{H})$ & $1769,21 \mathrm{~b}$ & $1223,92 \mathrm{~b}$ & $2314,50 \mathrm{~b}$ & $1,15^{\mathrm{ns}}$ & $23.827,29^{\mathrm{ns}}$ & 92,44 & IV \\
\hline SE $04(H)$ & $1680,38 \mathrm{~b}$ & $1324,31 \mathrm{~b}$ & $2036,45 \mathrm{c}$ & $0,88^{\mathrm{ns}}$ & $29.028,11 *$ & 86,53 & IV \\
\hline HT $01(\mathrm{H})$ & $1662,35 \mathrm{~b}$ & 1439,99 a & $1884,71 \mathrm{c}$ & $0,57^{6}$ & $-7,84^{\mathrm{ns}}$ & 87,59 & IV \\
\hline HT $14(\mathrm{H})$ & $1597,99 \mathrm{~b}$ & $1247,51 \mathrm{~b}$ & $1948,46 \mathrm{c}$ & $0,84^{\mathrm{ns}}$ & $4.207,68^{\mathrm{ns}}$ & 92,49 & IV \\
\hline HT $09(\mathrm{H})$ & $1554,02 \mathrm{~b}$ & $1270,90 \mathrm{~b}$ & $1837,14 \mathrm{c}$ & $0,58^{6}$ & $14.555,04^{\mathrm{ns}}$ & 80,25 & IV \\
\hline Catissol (V) & $1502,11 \mathrm{~b}$ & $1025,52 \mathrm{~b}$ & $1978,71 \mathrm{c}$ & $1,03^{\mathrm{ns}}$ & $48.239,90 * *$ & 85,95 & IV \\
\hline $\mathrm{MG}^{7}$ & 1832,09 & 1402,69 & 2261,49 & - & - & - & - \\
\hline $\mathrm{MT}^{8}$ & 2116,50 & 1687,00 & 2546,01 & - & - & - & - \\
\hline \multicolumn{8}{|l|}{$2001 / 2002$} \\
\hline Genótipo & MG & MD & MF & $\beta_{1}$ & $\sigma_{\mathrm{d}}^{2}$ & $\mathrm{R}^{2}$ & Classe \\
\hline M $734(\mathrm{H})$ & 2247,87 a & $1752,65 \mathrm{a}$ & $2545,00 \mathrm{a}$ & $0,98^{\mathrm{ns}}$ & $145.568,36^{* *}$ & 59,80 & I \\
\hline GV $26048(\mathrm{H})$ & $2150,31 \mathrm{a}$ & $1556,99 a$ & $2506,31 \mathrm{a}$ & $1,22^{6}$ & $19.073,41^{\mathrm{ns}}$ & 91,28 & I \\
\hline VDH 93 (H) & $1939,35 \mathrm{~b}$ & $1365,48 \mathrm{~b}$ & $2283,67 \mathrm{a}$ & $1,11^{\mathrm{ns}}$ & $-4.172,61^{\mathrm{ns}}$ & 96,05 & II \\
\hline CF $17(\mathrm{H})$ & $1921,67 \mathrm{~b}$ & $1377,79 \mathrm{~b}$ & $2248,00 \mathrm{a}$ & $0,86^{\mathrm{ns}}$ & $106.471,85^{* *}$ & 60,09 & II \\
\hline Agrobel $960(\mathrm{H})$ & $1816,96 \mathrm{~b}$ & $1453,03 \mathrm{a}$ & $2035,32 b$ & $0,85^{\mathrm{ns}}$ & $60.752,24 * *$ & 70,35 & III \\
\hline Exp $792(\mathrm{H})$ & $1761,77 \mathrm{~b}$ & $1247,88 \mathrm{~b}$ & $2070,11 \mathrm{~b}$ & $1,06^{\mathrm{ns}}$ & $33.413,52 * *$ & 84,80 & IV \\
\hline GV $26043(\mathrm{H})$ & $1688,24 \mathrm{~b}$ & $1166,54 \mathrm{~b}$ & $2001,26 b$ & $0,91^{\mathrm{ns}}$ & $53.006,08^{* *}$ & 74,75 & IV \\
\hline CF $13(\mathrm{H})$ & $1658,99 \mathrm{~b}$ & $1330,79 \mathrm{~b}$ & $1855,91 \mathrm{~b}$ & $0,90^{\text {ns }}$ & $190.132,43 * *$ & 49,60 & IV \\
\hline VDH $488(\mathrm{H})$ & $1657,41 \mathrm{~b}$ & 1139,92 b & $1967,90 \mathrm{~b}$ & $1,07^{\mathrm{ns}}$ & $-2.963,719^{\mathrm{ns}}$ & 95,37 & IV \\
\hline MG & 1871,39 & 1376,78 & 2168,16 & - & - & - & - \\
\hline MT & 2032,41 & 1602,84 & 2290,11 & - & - & - & - \\
\hline \multicolumn{8}{|l|}{$2003 / 2004$} \\
\hline Genótipo & MG & MD & MF & $\beta_{1}$ & $\sigma_{\mathrm{d}}^{2}$ & $\mathrm{R}^{2}$ & Classe \\
\hline ACA $884(\mathrm{H})$ & $2225,34 \mathrm{a}$ & $1998,13 \mathrm{a}$ & $2509,35 \mathrm{a}$ & $0,89^{\mathrm{ns}}$ & $43.343,50 * *$ & 72,54 & I \\
\hline M $734(\mathrm{H})$ & $2146,00 \mathrm{a}$ & $1724,75 \mathrm{a}$ & $2672,56 \mathrm{a}$ & $1,37^{6}$ & $186.555,74^{* *}$ & 65,50 & I \\
\hline ACA $885(\mathrm{H})$ & $1826,96 \mathrm{~b}$ & $1668,31 \mathrm{a}$ & $2025,28 b$ & $0,74^{6}$ & $227.378,36^{* *}$ & 31,85 & III \\
\hline A $972(\mathrm{H})$ & $1807,57 \mathrm{~b}$ & $1411,68 \mathrm{~b}$ & $2302,42 b$ & $1,17^{\mathrm{ns}}$ & $118.706,42 * *$ & 67,58 & IV \\
\hline ACA $872(\mathrm{H})$ & $1790,66 \mathrm{~b}$ & $1503,19 \mathrm{~b}$ & $2149,99 \mathrm{~b}$ & $0,96^{\mathrm{ns}}$ & $42.037,21 * *$ & 75,90 & III \\
\hline V $10034(\mathrm{H})$ & $1763,97 \mathrm{~b}$ & $1437,28 \mathrm{~b}$ & $2172,32 b$ & $0,89^{\text {ns }}$ & $36.671,22 * *$ & 74,97 & IV \\
\hline Agrobel $960(\mathrm{H})$ & $1756,72 \mathrm{~b}$ & 1529,54 b & $2040,69 \mathrm{~b}$ & $0,82^{\mathrm{ns}}$ & $23.965,22 *$ & 76,50 & III \\
\hline Helio $358(\mathrm{H})$ & $1683,92 \mathrm{~b}$ & $1352,02 \mathrm{~b}$ & $2098,80 \mathrm{~b}$ & $1,05^{\mathrm{ns}}$ & $79.190,53 * *$ & 70,25 & IV \\
\hline Catissol (V) & $1660,68 \mathrm{~b}$ & $1356,40 \mathrm{~b}$ & $2041,04 \mathrm{~b}$ & $1,01^{\mathrm{ns}}$ & $7.481,98^{\mathrm{ns}}$ & 88,90 & IV \\
\hline V $80198(\mathrm{H})$ & $1571,84 \mathrm{~b}$ & $1307,02 \mathrm{~b}$ & $1902,86 \mathrm{~b}$ & $0,88^{\mathrm{ns}}$ & $39.454,07 * *$ & 73,38 & IV \\
\hline Nutrissol (V) & $1562,94 \mathrm{~b}$ & $1151,86 \mathrm{~b}$ & $2076,80 \mathrm{~b}$ & $1,16^{\mathrm{ns}}$ & $77.922,34 * *$ & 74,47 & IV \\
\hline MG & 1799,69 & 1494,56 & 2181,10 & - & - & - & - \\
\hline MT & 1951,36 & 1627,14 & 2356,62 & - & - & - & - \\
\hline
\end{tabular}

${ }^{1}$ Avaliações realizadas em 2000/2001 incluíram os dados experimentais obtidos no Ensaio Final de Primeiro Ano 1999/2000 e Ensaio Final de Segundo Ano 2000/2001, com procedimento similar para os demais anos de avaliação. ${ }^{2}$ médias seguidas da mesma letra não diferem significativamente entre si, pelo teste de Scott e Knott, a 5\% de probabilidade. ${ }^{3} \mathrm{MD}=$ Média nos ambientes desfavoráveis. ${ }^{4} \mathrm{MF}=$ média nos ambientes favoráveis. ${ }^{5} \mathrm{H}=$ híbrido e $\mathrm{V}=$ variedade de polinização aberta. ${ }^{6}$ Significativo a $5 \%$ de probabilidade, pelo teste $\mathrm{T} ;{ }^{7} \mathrm{MG}=$ média geral. ${ }^{8} \mathrm{MT}=$ média das testemunhas. ${ }^{\text {ns }}$ Não significativo. * e $* *$ Significativo a $5 \%$ e a $1 \%$ de probabilidade, respectivamente pelo teste F.

Ciência Rural, v.39, n.9, dez, 2009. 
Tabela 3 - Parâmetros de adaptabilidade e estabilidade de genótipos de girassol, para rendimento de óleo ( $\mathrm{kg}^{-1}$ ), obtidos por meio dos métodos de PORTO et al. (2007), EBERHART \& RUSSEL (1966) e ROCHA et al. (2005), avaliados entre os anos de 2000 e 2004 .

\begin{tabular}{|c|c|c|c|c|c|c|c|}
\hline \multicolumn{8}{|c|}{ Rendimento de óleo $\left(\mathrm{kg} \mathrm{ha}^{-1}\right)$} \\
\hline \multicolumn{2}{|l|}{$2000 / 2001^{1}$} & \multicolumn{2}{|c|}{-----PORTO et al. (2007)----- } & \multicolumn{3}{|c|}{---EBERHART \& RUSSELL (1966)--- } & \multirow{2}{*}{$\begin{array}{c}\text { ROCHA et al. (2005) } \\
\text { Classe }\end{array}$} \\
\hline Genótipo & Média $^{2}$ & $\mathrm{MD}^{3}$ & $\mathrm{MF}^{4}$ & $\beta_{1}$ & $\sigma_{\mathrm{d}}^{2}$ & $\mathrm{R}^{2}$ & \\
\hline Agrobel $960(\mathrm{H})^{5}$ & $937,27 \mathrm{a}$ & $642,95 \mathrm{a}$ & $1084,44 \mathrm{a}$ & $1,10^{\mathrm{ns}}$ & $-2.352,03^{\mathrm{ns}}$ & 97,37 & I \\
\hline DK $4030(\mathrm{H})$ & $904,95 \mathrm{a}$ & $574,69 \mathrm{a}$ & $1070,08 \mathrm{a}$ & $1,09^{\text {ns }}$ & $35.566,27 * *$ & 67,54 & I \\
\hline M $734(\mathrm{H})$ & $879,28 \mathrm{a}$ & $510,00 \mathrm{a}$ & $1063,92 \mathrm{a}$ & $1,09^{\mathrm{ns}}$ & $37.115,93 * *$ & 66,65 & I \\
\hline Agrobel $930(\mathrm{H})$ & 873,13 a & $553,99 \mathrm{a}$ & $1032,70 \mathrm{a}$ & $1,11^{\mathrm{ns}}$ & $13.288,67 * *$ & 82,79 & I \\
\hline EM $677008(\mathrm{H})$ & $862,05 \mathrm{a}$ & $495,02 \mathrm{a}$ & $1045,57 \mathrm{a}$ & $1,11^{\mathrm{ns}}$ & $22.691,62 * *$ & 75,94 & II \\
\hline Agrobel $966(\mathrm{H})$ & $852,52 \mathrm{a}$ & 511,16 a & $1023,20 \mathrm{a}$ & $1,29^{6}$ & $5.903,79^{\mathrm{ns}}$ & 91,73 & $\mathrm{I}$ \\
\hline SE $04(\mathrm{H})$ & $784,53 \mathrm{~b}$ & $537,40 \mathrm{a}$ & $908,09 \mathrm{~b}$ & $1,02^{\text {ns }}$ & $5.926,15^{\mathrm{ns}}$ & 87,48 & III \\
\hline HT $01(\mathrm{H})$ & $744,17 \mathrm{~b}$ & 589,58 a & $821,46 b$ & $0,64^{6}$ & $2.026,42^{\text {ns }}$ & 81,34 & III \\
\hline HT $14(\mathrm{H})$ & $718,16 \mathrm{~b}$ & $485,54 \mathrm{a}$ & $834,47 \mathrm{~b}$ & $0,92^{\mathrm{ns}}$ & $2.152,24^{\mathrm{ns}}$ & 89,78 & IV \\
\hline HT $09(\mathrm{H})$ & $687,44 \mathrm{~b}$ & $551,42 \mathrm{a}$ & $755,46 \mathrm{~b}$ & $0,60^{6}$ & $6.183,71^{\mathrm{ns}}$ & 70,08 & III \\
\hline Catissol (V) & $636,86 \mathrm{~b}$ & $418,80 \mathrm{a}$ & $745,89 \mathrm{~b}$ & $0,97^{\mathrm{ns}}$ & $9.779,72 *$ & 82,24 & IV \\
\hline $\mathrm{MG}^{6}$ & 807,30 & 533,68 & 944,11 & - & - & - & - \\
\hline $\mathrm{MT}^{7}$ & 908,27 & 576,47 & 1074,18 & - & - & - & - \\
\hline \multicolumn{8}{|l|}{$2001 / 2002$} \\
\hline Genótipo & MG & MD & MF & $\beta_{1}$ & $\sigma_{\mathrm{d}}^{2}$ & $\mathrm{R}^{2}$ & Classe \\
\hline M $734(\mathrm{H})$ & $917,72 \mathrm{a}$ & $707,70 \mathrm{a}$ & $1043,73 \mathrm{a}$ & $0,99^{\mathrm{ns}}$ & $27.043,25^{* *}$ & 63,53 & I \\
\hline GV $26048(\mathrm{H})$ & $872,31 \mathrm{a}$ & 610,96 a & $1029,11 \mathrm{a}$ & $1,22^{6}$ & $2.644,54^{\mathrm{ns}}$ & 92,84 & I \\
\hline CF $17(\mathrm{H})$ & $813,82 \mathrm{a}$ & 547,43 a & $973,65 \mathrm{a}$ & $0,90^{\mathrm{ns}}$ & $28.122,84^{* *}$ & 58,30 & II \\
\hline VDH $93(\mathrm{H})$ & $801,42 \mathrm{a}$ & $538,02 \mathrm{a}$ & 959,46 a & $1,11^{\mathrm{ns}}$ & $748,56^{\mathrm{ns}}$ & 93,93 & II \\
\hline Agrobel $960(\mathrm{H})$ & $789,58 \mathrm{a}$ & $636,21 \mathrm{a}$ & 881,61 a & $0,84^{\mathrm{ns}}$ & $15.565,12 * *$ & 66,40 & III \\
\hline $\operatorname{Exp} 792(\mathrm{H})$ & $776,68 \mathrm{a}$ & $537,85 \mathrm{a}$ & 919,98 a & $1,07^{\mathrm{ns}}$ & $10.072,08 * *$ & 81,83 & IV \\
\hline CF $13(\mathrm{H})$ & $752,46 \mathrm{a}$ & $598,12 \mathrm{a}$ & $845,06 \mathrm{a}$ & $0,88^{\mathrm{ns}}$ & $39.754,48 * *$ & 49,10 & IV \\
\hline VDH $488(\mathrm{H})$ & $744,25 \mathrm{a}$ & $508,05 \mathrm{a}$ & $885,97 \mathrm{a}$ & $1,09^{\mathrm{ns}}$ & $1.263,08^{\mathrm{ns}}$ & 92,98 & IV \\
\hline GV $26043(H)$ & $717,53 \mathrm{a}$ & $481,81 \mathrm{a}$ & $858,96 \mathrm{a}$ & $0,86^{\mathrm{ns}}$ & $11.460,79 * *$ & 72,91 & IV \\
\hline MG & 798,41 & 574,01 & 933,05 & - & - & - & - \\
\hline MT & 853,65 & 671,95 & 962,67 & - & - & - & - \\
\hline \multicolumn{8}{|l|}{$2003 / 2004$} \\
\hline Genótipo & MG & MD & MF & $\beta_{1}$ & $\sigma_{\mathrm{d}}^{2}$ & $\mathrm{R}^{2}$ & Classe \\
\hline ACA $884(\mathrm{H})$ & $851,84 \mathrm{a}$ & $743,84 \mathrm{a}$ & $986,83 \mathrm{a}$ & $0,89^{\mathrm{ns}}$ & $9.957,83 * *$ & 70,13 & I \\
\hline M $734(\mathrm{H})$ & $786,12 \mathrm{a}$ & $632,09 \mathrm{a}$ & $978,65 \mathrm{a}$ & $1,14^{\mathrm{ns}}$ & $19.598,90 * *$ & 69,59 & I \\
\hline A $972(\mathrm{H})$ & $773,39 \mathrm{a}$ & $586,10 \mathrm{a}$ & $1007,50 \mathrm{a}$ & $1,16^{\mathrm{ns}}$ & $24.711,95^{* *}$ & 65,94 & II \\
\hline ACA $872(\mathrm{H})$ & $749,78 \mathrm{a}$ & $615,58 \mathrm{a}$ & $917,52 \mathrm{a}$ & $1,08^{\mathrm{ns}}$ & $10.292,33 * *$ & 77,22 & III \\
\hline Helio $358(\mathrm{H})$ & $736,15 \mathrm{a}$ & $571,64 \mathrm{a}$ & $941,77 \mathrm{a}$ & $1,07^{\mathrm{ns}}$ & $14.091,93 * *$ & 72,50 & II \\
\hline ACA $885(\mathrm{H})$ & $731,60 \mathrm{a}$ & $649,92 \mathrm{a}$ & $833,69 \mathrm{~b}$ & $0,85^{\mathrm{ns}}$ & $34.335,64 * *$ & 43,66 & III \\
\hline Agrobel $960(\mathrm{H})$ & $730,84 \mathrm{a}$ & 619,79 a & $869,65 \mathrm{~b}$ & $0,83^{\mathrm{ns}}$ & $2.920,83^{\mathrm{ns}}$ & 80,99 & III \\
\hline Catissol (V) & $655,10 \mathrm{a}$ & $518,64 \mathrm{~b}$ & $825,68 \mathrm{~b}$ & $0,94^{\mathrm{ns}}$ & $-505,14^{\mathrm{ns}}$ & 91,92 & IV \\
\hline V $10034(\mathrm{H})$ & $650,52 \mathrm{a}$ & $500,96 \mathrm{~b}$ & $837,46 \mathrm{~b}$ & $0,93^{\mathrm{ns}}$ & $5.600,00 *$ & 79,10 & IV \\
\hline V $80198(\mathrm{H})$ & $646,69 \mathrm{a}$ & $514,36 \mathrm{~b}$ & $812,10 \mathrm{~b}$ & $0,96^{\mathrm{ns}}$ & $8.150,08 * *$ & 76,10 & IV \\
\hline Nutrissol (V) & 586,16 a & $413,08 \mathrm{~b}$ & $802,50 \mathrm{~b}$ & $1,10^{\mathrm{ns}}$ & $9.768,35 * *$ & 78,46 & IV \\
\hline $\mathrm{MG}$ & 718,01 & 578,72 & 892,12 & - & - & - & - \\
\hline MT & 758,48 & 625,94 & 924,15 & - & - & - & - \\
\hline
\end{tabular}

${ }^{1}$ Avaliações realizadas em 2000/2001 incluíram os dados experimentais obtidos no Ensaio Final de Primeiro Ano 1999/2000 e Ensaio Final de Segundo Ano 2000/2001, com procedimento similar para os demais anos de avaliação. ${ }^{2}$ médias seguidas da mesma letra não diferem significativamente entre si, pelo teste de Scott e Knott, a $5 \%$ de probabilidade. ${ }^{3} \mathrm{MD}=$ Média nos ambientes desfavoráveis. ${ }^{4} \mathrm{MF}=$ média nos ambientes favoráveis. ${ }^{5} \mathrm{H}=$ híbrido e $\mathrm{V}=$ variedade de polinização aberta. ${ }^{6}$ Significativo a $5 \%$ de probabilidade, pelo teste $\mathrm{T} ;{ }^{7} \mathrm{MG}=$ média geral. ${ }^{8} \mathrm{MT}=$ média das testemunhas. ${ }^{\text {ns }}$ Não significativo. * $\mathrm{e} * *$ Significativo a $5 \%$ e a $1 \%$ de probabilidade, respectivamente pelo teste $\mathrm{F}$. 
Dentre os genótipos selecionados pelo método de PORTO et al. (2007), os híbridos EM 677008 (2002/2001), Agrobel 930 (2000/2001) e GV 26048 (2001/2002) foram estáveis para rendimento de grãos, e HT 01 (2000/2001) e GV 26048 (2001/2002), para rendimento de óleo. Essa estabilidade foi evidenciada pelos desvios da regressão (s2d) não significativos ou pelos valores do coeficiente de determinação acima de $80 \%$ (Tabelas 2 e 3 ).

Resultados obtidos segundo a metodologia proposta por ROCHA et al. (2005) classificaram, para rendimento de grãos, os genótipos EM 677008 (2000/ 2001), DK 4030 (2000/2001), GV26048(2001/2002)eACA 884 (2003/2004), com adaptabilidade geral, Agrobel 930 (2000/2001), VDH 93 (2001/2002) e CF 17 (2001/2002), com adaptabilidade a ambientes favoráveis, e ACA 885 (2003/2004) e ACA $872(2003 / 2004)$ para os desfavoráveis. Para rendimento de óleo, DK 4030 (2000/ 2001), Agrobel 930 (2000/2001), Agrobel 966 (2000/ 2001), GV 26048 (2001/2002) e ACA 884 (2003/2004) tiveram adaptabilidade geral, EM 677008 (2000/2001), CF 17 (2001/2002), VDH 93 (2001/2002), A972 (2003/ 2004) e Helio 358 (2003/2004) apresentaram adaptabilidade aos ambientes favoráveis e SE 04 (2000/ 2001), HT 01 (2000/2001), HT 09 (2000/2001), ACA 872 (2003/2004) e ACA 885 (2003/2004), aos desfavoráveis (Tabelas 2 e 3 ).

O método de ROCHA et al. (2005) selecionou um número maior de genótipos para os dois componentes de rendimento, em relação ao método de PORTO et al. (2007) e o de EBERHART \& RUSSELL (1966) (Tabelas 2 e 3). Na safra 2000/2001, por exemplo, somente dois genótipos não foram selecionados para um tipo de ambiente pelo método de ROCHA et al. (2005) (Classe I, II ou III), quanto a rendimento de óleo, enquanto que, pelo método de PORTO et al. (2007), somente HT 01 foi selecionado para ambientes desvaforáveis e, pelo método de EBERHART \& RUSSELL (1966), nenhum genótipo se destacou (Tabela 3). Isso se deve ao critério (média das testemunhas) estabelecido para os métodos de PORTO et al. (2007) e EBERHART \& RUSSELL (1966) na comparação dos desempenhos produtivos dos genótipos. Segundo PORTO et al. (2007), além da média das testemunhas, a comparação pode ser feita, por exemplo, em relação à melhor testemunha ou média geral. Nesse caso, a seleção será mais ou menos rigorosa, respectivamente, pois ter-se-á um menor ou maior número de genótipos com indicação geral ou específica a um tipo de ambiente. Nesse estudo, a seleção dos genótipos pelo método de ROCHA et al. (2005) teria tido uma maior similaridade em relação ao método de PORTO et al. (2007) se a média geral do ensaio tivesse sido utilizada como ponto de referência. Assim, o método de PORTO et al. (2008) foi mais rigoroso em selecionar os genótipos, em relação ao método de ROCHA et al. (2005).

\section{CONCLUSÕES}

Para a região subtropical do Brasil, o genótipo ACA 884 obteve indicação geral para rendimento de grãos, enquanto EM 677008, Agrobel 930 e GV 26048 foram indicados para ambientes favoráveis, e ACA 885, para os desfavoráveis. Para rendimento de óleo, ACA 884 teve indicação geral, GV 26048, CF 17, A 972 e Helio 358 foram indicados para ambientes favoráveis, e HT 01 e ACA 885, para os desfavoráveis.

\section{REFERÊNCIAS}

CARVALHO, C.G.P de. Informes da avaliação de genótipos de girassol 2006/2007 e 2007. Londrina: Embrapa Soja, 2008. 108 p. (Embrapa Soja. Documentos, 295).

CARVALHO, C.G.P. et al. Categorizing coefficients of variation in sunflower trials. Crop Breeding and Applied Biotechnology, v.3, n.1, p.69-76, 2003. Disponível em: $<$ http://www.sbmp.org.br/cbab/siscbab/uploads/c8128f42-9baa9413.pdf>. Acesso em 29 jul. 2009.

CRUZ, C.D. Programa genes: versão Windows; aplicativo computacional em genética e estatística. Viçosa: UFV, 2001. 648p.

CRUZ, C.D.; CARNEIRO, P.C.S. Modelos biométricos aplicados ao melhoramento genético. Viçosa: UFV, 2003. $585 \mathrm{p}$.

DE LA VEGA, A.J.; CHAPMAN, S.C. Defining sunflower selection strategies for a highly heterogeneous target population of environments. Crop Science, v.46, p.136-144, 2006.

EBERHART, S.A.; RUSSELL, W.A. Stability parameters for comparing varieties. Crop Science, v.6, n.1, p.36-40, 1966. Disponível em: <http://crop.scijournals.org/cgi/content/abstract/ 6/1/36>. Acesso em 29 jul. 2009.

ESTADOS UNIDOS. Department of Agriculture. Foreign Agricultural Service. Oilseeds: world market and trade. Washington, 2008. 34p. (Circular Series, FOP 2-08).

LU'QUEZ, J.E. et al. Stability and adaptability of cultivars in non-balanced yield trials. Comparison of methods for selecting 'high oleic' sunflower hybrids for grain yield and quality. Journal of Agronomy and Crop Science, v.188, n.4, p.225-234, 2002. Disponível em: <http://www3.interscience.wiley.com/ journal/118955374/issue $>$. Acesso em 29 jul. 2009. doi: 10.1046/j.1439-037X.2002.00562.x.

PIMENTEL, G. Curso de estatística experimental. 13.ed. São Paulo: USP-Esalq, 1985. 486p. 
PORTO, W.S. et al. Adaptabilidade e estabilidade como critérios para seleção de genótipos de girassol. Pesquisa Agropecuária Brasileira, v.42, n.4, p.491-499, 2007. Disponível em: <http:/ /webnotes.sct.embrapa.br/pdf/pab2007/04/42n04a06.pdf $>$. Acesso em 29 jul. 2009.

PORTO, W.S. et al. Evaluation of sunflower cultivar for central Brazil. Scientia Agricola. v.65, p.139-144, 2008. Disponível em: $<$ http://www.scielo.br /scielo.php?script $=$ sci_arttext\&pid=S010390162008000200005\&lng=en\&nrm=iso $>$. Acesso em 29 jul. 2009. doi: $10.1590 / \mathrm{S} 0103-90162008000200005$.
REUNIÃO NACIONAL DE PESQUISA DE GIRASSOL, 16. 2007, Uberaba. Ata... Londrina: Embrapa Soja, 2007. 105p. (Embrapa Soja. Documentos, 298).

ROCHA R.B. et al. Avaliação do método centróide para estudo de adaptabilidade ao ambiente de clones de Eucalyptus grandis. Ciência Florestal, v.15, p.255-266, 2005. Disponível em: $<$ http://www.ufsm.br/cienciaflorestal/artigos/v15n3/ A5V15N3.pdf>. Acesso em 29 jul. 2009.

VERMA, M.M. et al. Limitations of conventional regression analysis: a proposed modification. Theoretical and Applied Genetics, v.53, n.2, p.89-91, 1978 . 